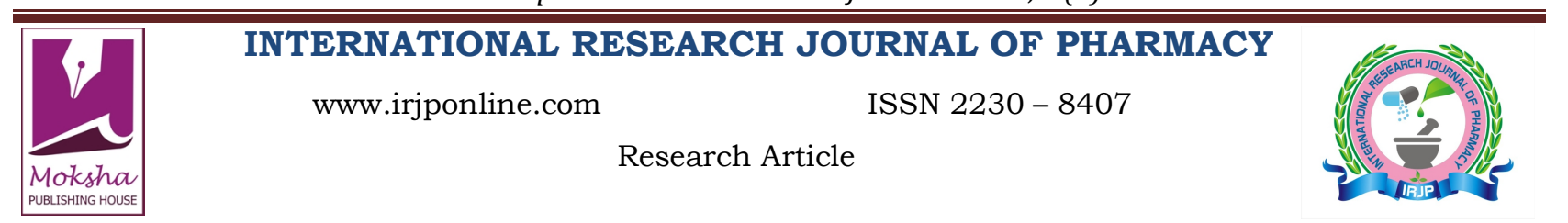

\title{
EXPERIMENTAL STUDIES ON ACTIVE METABOLITES OF CALOTROPIS GIGANTEA FOR EVALUATION OF POSSIBLE ANTIFUNGAL PROPERTIES
}

\author{
Mandepudi David ${ }^{1,2} *$, RavuruBharath Kumar $^{3}$, Mandepudi Bhavani ${ }^{2}$
}

${ }^{1}$ Faculty of Biotechnology, Jawaharlal Nehru Technological University-Hyderabad, Hyderabad, Andhra Pradesh, India

${ }^{2}$ Department of Biotechnology, School of Engineering, Sir Padampat Singhania University, Udaipur-313601, Rajasthan, India

${ }^{3}$ School of Biotechnology, Vignan University, Guntur - 522213, Andhra Pradesh, India

*Corresponding Author Email: david.mandepudi@gmail.com

Article Received on: 18/03/13 Revised on: 01/04/13 Approved for publication: 11/05/13

DOI: $10.7897 / 2230-8407.04553$

IRJP is an official publication of Moksha Publishing House. Website: www.mokshaph.com

(C) All rights reserved.

\begin{abstract}
The active metabolites like phytochemicals from the medicinal plants were under exploration for the development of novel and biodegradable effective drugs as an alternative to the ineffective contemporary medicine. In the similar lines, the Calotropis gigantea leaves, buds and flowers were extracted for the active metabolites using ethanol, methanol, chloroform and aqueous solvents and then these solvent extracts of $100 \mu \mathrm{l}(25 \mu \mathrm{g} / \mathrm{ml}) \mathrm{were}$ tested separately for the in vitro antifungal activity against the test pathogenic fungi viz. Aspergillus niger, Rhizoctonia oryzae-sativae, Fusarium solani and Trichoderma viride. In the results ethanol buds extract has shown the highest growth reducing activity $(67.82 \%)$ on Fusarium solani where the positive control, clotrimazole (10 $\mu$ g/ml) recorded $58 \%$ growth reduction. Similarly aqueous buds extract has shown $\sim 66 \%$ growth reduction on Rhizoctonia oryzae-sativae where Clotrimazole, the positive control has shown the maximum growth reduction capability $(\sim 73 \%)$; however all the aqueous extracts exhibited the growth reduction capabilities on all the test fungi. On the contrary methanol leaves extract increased the growth of Aspergillus niger by $85 \%$; and similarly chloroform leaves and buds extracts exhibited the growth supporting activity on Rhizoctonia oryzae-sativae (32\%) and Trichoderma viride (34\%) respectively. This study brings out the mixed results of Calotropis gigantean solvent extracts as antifungal drugs and hence makes a caution on the knowledgeable and judicious use of these extracts as a medicine as evident among the folklores. Further it is also advised to make advanced studies in the similar line for the effective utilization of this Calotropis species in either directions to serve the mankind.
\end{abstract}

Keywords: Antifungal, Calotropis, Solvent extracts, Active metabolites, Phytochemicals

\section{INTRODUCTION}

Plant based active metabolites are under intensive exploration around the world among the scientific community ${ }^{1-5}$ to supplement the contemporary medicinal practices with the plant and evidence based drugs as they have minimal side effects and folklore reputation. In this pursuit several plant based drugs and remedies were reported and still there exists vast potential to identify and explore the possible medicine from the herbal plants. The secondary metabolites were the most drug like molecules targeted in several investigations and they were proved to be fruitful in developing the potential drugs ${ }^{6}$. However the efforts in this line were limited mostly to the safest herbal medicines in terms of handling and processing ${ }^{7-8}$; so there can also be an alternative approach to choose the other plant sources like Calotropis species to explore the potential antimicrobial active metabolites ${ }^{9-12}$ that may provide the latent drugs for animals, plants and even humans ${ }^{13}$. This Calotropis species having two variants viz. Calotropis procera and Calotropis gigantea, known for its poisonous nature, were least explored milk weeds with lot of secondary active metabolites in the form of latex in leaves, buds and to some extent in the flowers. Among these two variants Calotropis procera ${ }^{14-20}$ has been explored to some extent for the medicinal properties but the Calotropis gigantea had the less exposure in the scientific investigations. So the present investigation reports the experimental studies to elucidate the possible antifungal properties of Calotropis gigantea aqueous and non-aqueous leaves, buds and flowers extracts on selected pathogenic fungi.

\section{MATERIALS AND METHODS}

Extracts of Calotropis gigantea

The solvent extracts of Calotropis gigantea leaves, buds \& flowers were prepared with ethanol, methanol, chloroform and aqueous solvents by soxhlet solvent extraction method and estimated the residual extract concentrations ${ }^{21}$. These solvent extracts of ethanol leaves (EL), ethanol buds (EB), ethanol flowers (EF), methanol leaves (ML), methanol buds (MB), methanol flowers (MF), chloroform leaves (CL), chloroform buds (CB), chloroform flowers (CF), Aqueous leaves (AL), Aqueous buds (AB)and Aqueous flowers (AF) were stored in the refrigerator until use.

\section{Test Fungal Cultures}

The fungal cultures Rhizoctonia oryzae-sativae(MTCC 2162), Aspergillus niger (MTCC 1344), Fusarium solani (MTCC 2671), and Trichoderma viride (MTCC 793) were procured from Microbial Type Culture Collection and Gene Bank (MTCC), Chandigarh, India and used them as the test fungi for the evaluation of Calotropis gigantea solvent extracts.All these fungal cultures were periodically subculture and maintained in the Microbiology laboratory, Department of Biotechnology, School of Engineering, Sir Padampat Singhania University, Udaipur, Rajasthan, India.

\section{Inoculum and Media Preparation}

The fungal spores were dispersed aseptically in $1 \%$ sterile saline solution to get the spore inoculum of $10^{5} \mathrm{cfu} / \mathrm{ml}$ and used it as inoculum for the respective fungal cultures, in triplicates. The potato dextrose (PD) broth cultures inoculated with $100 \mu \mathrm{l}$ of solvent extract with residual concentration of $25 \mu \mathrm{g} / \mathrm{ml}$ from each sample separately except the control and the positive control (broth media added with $100 \mu \mathrm{l}$ of $10 \mu \mathrm{g} / \mathrm{ml}$ clotrimazole, as the standard antifungal drug) with respect to each test fungus were sterilized by autoclaving at $121^{\circ} \mathrm{C}$ for $15 \mathrm{~min}$. and subsequently used these prepared sterile PD media for the tests. 


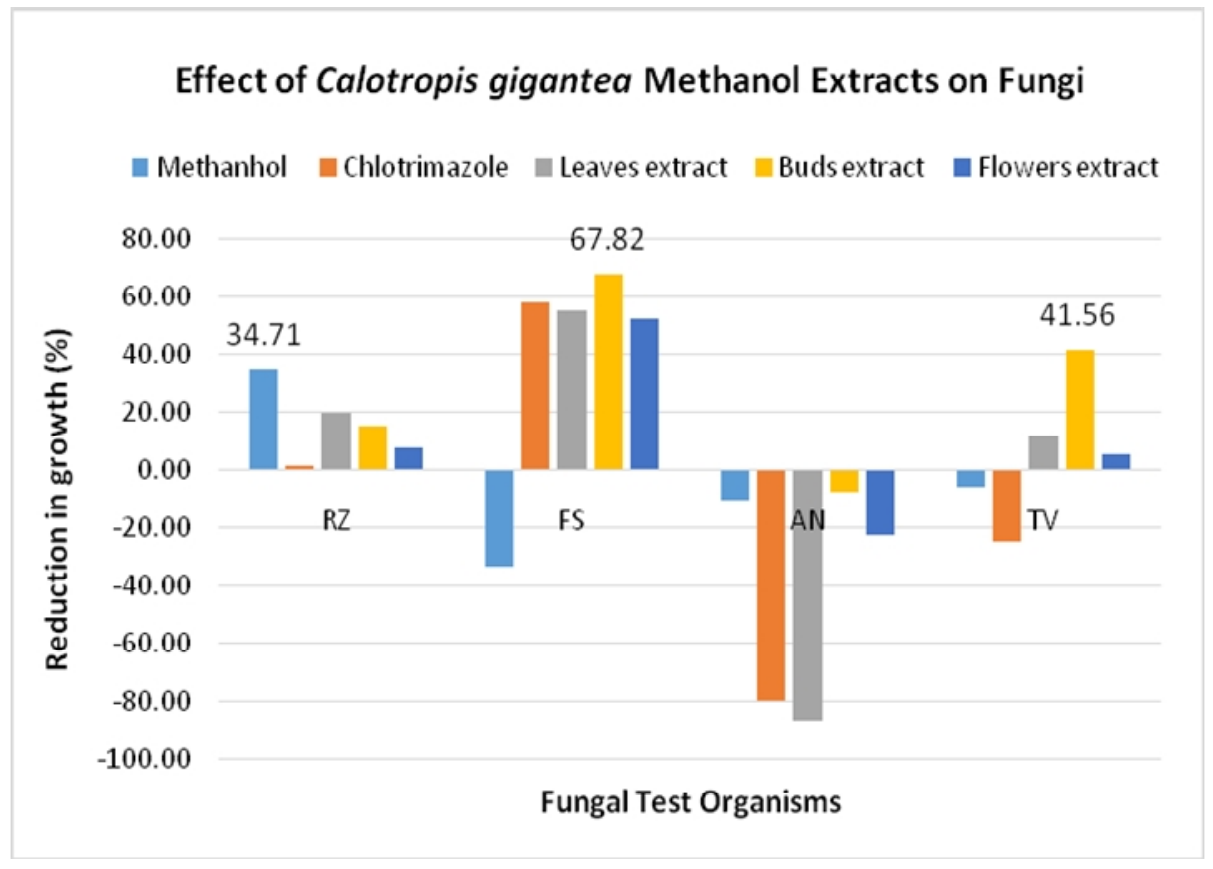

Figure 1: Effects of Calotropis gigantea methanol extracts on the growth and survival of Rhizoctonia oryzae-sativae (RZ), Fusarium solani (FS), Aspergillus niger (AN) and Trichoderma viride (TV)

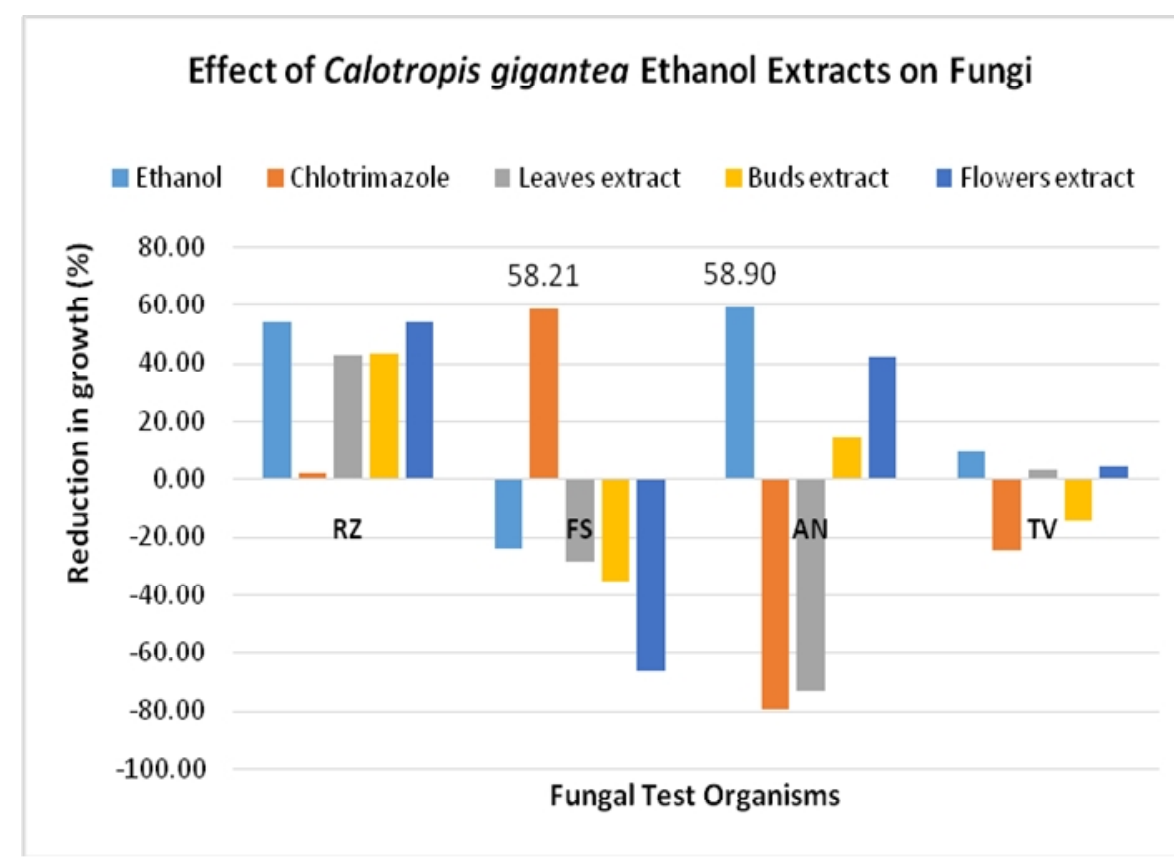

Figure 2: Effects of Calotropis gigantea ethanol extracts on the growth and survival of Rhizoctonia oryzae-sativae (RZ), Fusarium solani (FS), Aspergillus niger (AN) and Trichoderma viride (TV) 


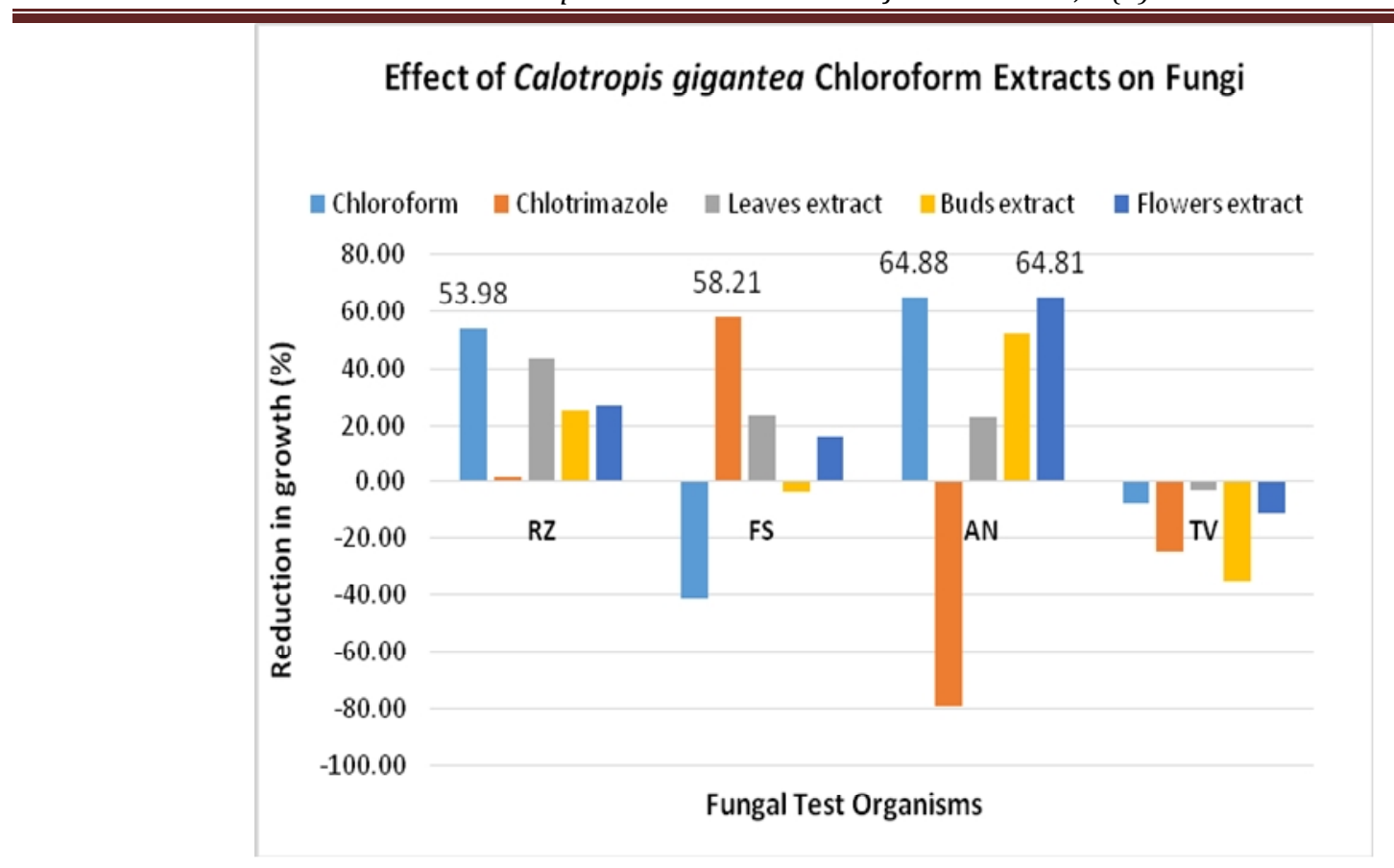

Figure 3: Effects of Calotropis gigantea chloroform extracts on the growth and survival of Rhizoctonia oryzae-sativae (RZ), Fusarium solani (FS), Aspergillus niger (AN) and Trichoderma viride (TV)

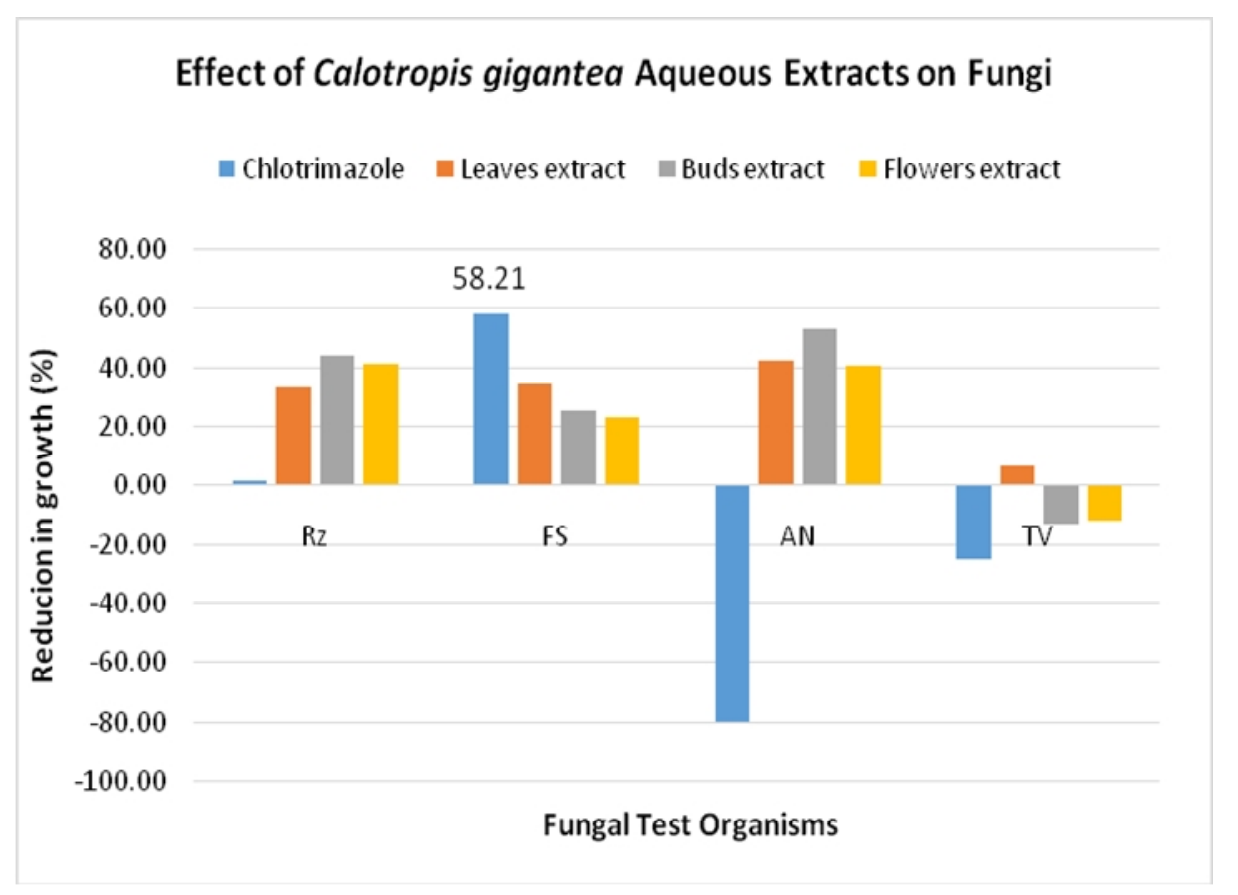

Figure 4: Effects of Calotropis gigantea aqueous extracts on the growth and survival of Rhizoctonia oryzae-sativae (RZ), Fusarium solani (FS), Aspergillus niger (AN) and Trichoderma viride (TV)

\section{Broth Culturing of Test Fungi}

The prepared sterile PD broth media were inoculated with $100 \mu$ l of the respective prepared fungal spore suspension $\left(10^{5} \mathrm{cfu} / \mathrm{ml}\right)$ aseptically including the positive controls and negative controls. These spore inoculated media were incubated in an orbital shaker incubator at $120 \mathrm{rpm}, 30^{\circ} \mathrm{C}$ for $48 \mathrm{hrs}$.

\section{Estimation of Biomass}

The fungal biomass ${ }^{5,22}$ grown upto 48 hrs., were filtered through the pre-weighed Whatman filter papers separately and the residual biomass on the filter papers for each culture were dried in the oven at $60^{\circ} \mathrm{C}$ for overnight and then the final dry weight was measured along with the filter paper. The differential fungal dry mass were calculated on the basis of control for each sample and used themto plot the growth reduction(\%) profiles of Calotropis gigantea solvent extracts against the test pathogenic fungal organisms as shown in the Figures $1-4$.

\section{RESULTS}

The effect of methanol extracts of Calotropis gigantea as shown in Fig-1, has brought out the buds extract as the highest growth reducing $(67.82 \%)$ extract with respect to 
Fusarium solani; otherwise also, the leaves extract as well as the flowers extract has the comparable growth reduction ${ }^{23-24}$ capacity $(\sim 52 \%)$ with that of the positive control, clotrimazole (58\%). Similarly, the buds extract has recorded the second best growth reducing methanol extract (41.56\%) on Trichoderma viride. But then both leaves and flowers extracts have shown mild growth reduction effects on Trichoderma viride. On the contrary, none of the methanol extracts, including controls, has positive growth reduction effects on Aspergillus niger and further they were found to support the growth and especially leaves extract has shooted the increase in growth to about $85 \%$. The ethanol extracts of Calotropis gigantea seem to be having almost no growth reduction capabilities (Fig. 2) on any of the test fungal organisms, owing to the fact that the methanol, negative control, has exhibited the maximum reduction capability on all the test fungi except Fusarium solani, where conversely ethanol flowers extracts exhibited the highest growth promoting capacity followed by ethanol buds and leaves extracts respectively. Similarly the ethanol buds extract has the growth promoting capability for soil born Trichoderma viride, whereas the ethanol leaves and flowers extracts has mildgrowth reducing capabilities on this fungus.

The chloroform extracts of Calotropis gigantea, like that of ethanol extracts, were found to have no growth reducing capabilities on these test fungi except Fusarium solani as shown in the Fig-3; where the chloroform leaves \& flowers extracts have the slight growth reduction $(\sim 20 \%)$ capabilities on Fusarium solani, whereas the positive control clotrimazole had the $58.21 \%$ of growth reduction capacity. On the other hand the chloroform leaves and buds extracts have the growth promoting capabilities on Rhizoctonia oryzae-sativae (32\%) and Trichoderma viride (34\%) respectively.

The aqueous Calotropis gigantea extracts as shown in the Fig-4, exhibited growth reduction capabilities on all test fungi except Trichoderma viride, where only aqueous leaves extract has mild growth reduction capability $(\sim 5 \%)$ and other aqueous buds \& flowers extracts supportedthe growth $(\sim 10 \%)$. Similarly, aqueous extracts have demonstrated (4050) $\%$ of growth reduction on Aspergillus niger. Further these aqueous extracts have shown (20-30) \% growth reduction on Fusarium solani ${ }^{25}$ and (30-40) \% growth reduction on Rhizoctonia oryzae-sativae.

\section{DISCUSSION}

Theaqueous extracts of Calotropis gigantea produced growth reduction on Rhizoctonia oryzae-sativae (30-40)\%, Fusarium solani (20-30)\% and Aspergillus niger (40-50) \% ; which imply that Calotropis gigantean produces water soluble metabolites that could restrict the growth of fungus and protect itself from the decay. Further methanol extractsand aqueous extracts have demonstratedhigher and moderate growth reduction potential on Fusarium solani, respectively; whereas chloroform extracts had mild growth reduction potential on it and on the contrary, ethanol extracts had growth supporting effects on Fusarium solani. Such kind of mixed response may be due to the proportionate distribution of respective metabolites for restriction and provision of plant based nutrients for these fungi. Similar results were also observed in the case of Aspergillus niger, whereas methanol buds \& leaves extracts exhibited moderate \& mild growth reduction potential on Trichoderma viride, but all other extracts favored the growth of Trichoderma viride. These results also suggests the proportionate distribution of
Calotropis gigantea active metabolites which may help to protect the plant during the vegetative or propagative phase and some metabolites may favor the growth of fungi during the degradation of wornout or shed plant materials ${ }^{26}$. In addition, it may also be inferred that the support of Calotropis gigantea extracts for the growth of Trichoderma viride helps in reduction of soil born fungal diseases as Trichoderma viride was also found to act as a biological control against soil born fungal diseases ${ }^{27-28}$. Perhaps this was the reason for the use of Calotropis gigantea leaves as the green manure in the seedling bed to grow the seedlings and as manure for coconut plantations ${ }^{29}$.

\section{CONCLUSIONS}

The studied Calotropis gigantea solvent extracts effects on the growth of pathogenic test fungal organisms revealed that, aqueous extracts of leaves, buds and flowers had the growth reduction potential except on Trichoderma viride, which may be the strategy of the plant to protect itself from these pathogenic fungi during the vegetative phase. These results are instrumental to understand the traditional practice of Calotropis gigantea aqueous extracts fresh leaves \& latex preparations and their use as a medicine among many ethnic groups in the world. On the other hand the non-aqueous ethanol, methanol \& chloroform extracts had the mixed distribution of the active metabolites from the Calotropis gigantea leaves, buds \& flowers and hence necessitates the knowledge and caution in using these plant materials as part of the medicine and such knowledge has been with the traditional healers among the ethnic groups around the word. So, it would be of interest for scientific community and the society at large to have similar studies on the active metabolites in the extracts of Calotropis species to understand the traditional drug practices and to explore the possibilities of potential drugs for contemporary medical practice.

\section{ACKNOWLEDGEMENT}

Dr. M Lakshmi Narasu, Professor \& Dr. ArchanaGiri, Assistant Professor, Faculty of Biotechnology, Jawaharlal Nehru Technological University, Hyderabad; Dr. Archana Gajbhiye, Head, Department of Biotechnology, Sir Padampat Singhania University, Udaipur were acknowledged for their suggestions and critical comments on the research work. Mr. Ashok Ghosh, President, Ms. Rinu Ghosh, Vice President, Prof. P.C. Deka, Vice Chancellor and Prof. Achintya Chaudary, Dean, School of Engineering of Sir Padampat Singhania University, Udaipur were also greatly acknowledged and thanked for their support and approvals for the research work.

\section{REFERENCES}

1. Koehn FE, Carter GT. The evolving role of natural products in drug discovery. Nat. Rev. Drug Discov., 2005; 4:206-220. http://dx.doi.org/ 10.1038/nrd1657 PMid:15729362

2. Balunas MJ,Kinghorn AD. Drug discovery from medicinal plants. Life Sci., 2005; 78:431-441. http://dx.doi.org/10.1016/j.1fs.2005.09.012 PMid:16198377

3. Anupam G, Bidus KD, Soroj KC, Goutam C. Antibacterial potentiality and phytochemical analysis of mature leaves of Polyalthialongifolia(Magnoliales: Annonaceae).The South Pacific Journal of Natural Science2008; 26:68-72. http://dx.doi.org/ 10.1071/SP08011

4. Wakirwa JH, Ibrahim P, Madu SJ. Phytochemical screening and in vitro antimicrobial analysis of the ethanol stem bark extract of Jatropacurcas Linn. (Euphorbiaceae). International Research Journal of Pharmacy 2013; 4(3):97-100. http://dx.doi.org/10.7897/2230-8407.04317

5. Javid IP. Antifungal activity and phytochemical screening of plant species from northern India.World journal of pharmacy and pharmaceutical sciences2012; 1(2):810-819.

6. Balandrin MF, Klocke JA, Wurtele ES, Bollinger WH. Natural plant chemicals: Sources of industrial and medicinal materials. Science1985; 228:1154-60. http://dx.doi.org/10.1126/science.3890182 PMid:3890182 
7. Majaw S,Moirangthem J. Quantitative and qualitative analysis of Clerodendroncolebrookianumwalp. Leaves and Zingibercassumunar Roxb. Rhizomes. Ethnobotanical Leaflets2009; 13:578-89.

8. Veronese P, Li X, Niu X, Weller SC, BressanRA, Hasegawa PM. Bioengineering mint crop improvement. Plant Cell, Tissue and Organ Culture2001; 64:133-144.http://dx.doi.org/10.1023/A:1010649207445

9. CordellGA. Biodiversity and drug discovery: A symbiotic relationship. Phytochemistry 2000; 55:463-480. http://dx.doi.org/10.1016/ S00319422(00)00230-2

10. Maueen KK, RanaAC, DixitVK. Calotropis species: A Comprehensive Review. Phoog Mag Plant Rev., 2005; 1(2):48-52.

11. Sharma GK. Calotropis procera and Calotropis gigantea. Indian journal of veterinary science 1934;4:63-74.

12. Mueen AK, RanaKAC, Dixit VK. Studies on Calotropis species for antimyocardial infections activity in albino rats. Indian Drugs2002; 39(11):613-615.

13. Falguni KS, Parabia MH. Ethnobotanical studies and validation of lead: a case study on evaluation of Calotropissp. on dermal fungal infections. International journal of pharmacy \& life sciences2011; 2(6):797-800.

14. Nighat B, Sharma B, PandeyRS. Evaluation of insecticidal efficacy of Calotropis procera andAnnona squamosal ethanol extracts against Muscadomestica.Journal ofBiofertilizers\&biopesticides 2010;1(1):1-6.

15. Shanti SK, Nagamalleswari SK, Chaitra D, Yasodamma N. Traditional use of Calotropis procera R. Br. against migraine.Current science 2011; 101(9):1120-1121.

16. Dewan S, SangraulaH, Kumar VL. Preliminary studies on the analgesic activity of latex of Calotropis procera. Journal of Ethnopharmacology 2000; 73:307-311. http://dx.doi.org/10.1016/S0378-8741(00)00272-5

17. Kumar S, Dewan S, SangraulaH, Kumar VL. Anti-diarrhoeal activity of latex of Calotropis procera. Journal of Ethnopharmacology 2001;76:115-118. http://dx.doi.org/10.1016/S0378-8741(01)00219-7

18. Kumar VL,Shivka YM. In vivo and in vitro effect of latex of Calotropis procera on gastrointestinal smooth muscles. Journal of Ethnopharmacology2004;93:377-379.http://dx.doi.org/ 10.1016/j.jep.2004.04.013 PMid:15234780

19. Roy S, Sehgal R, PadhyBM, Kumar VL. Antioxidant and protective effect of latex of Calotropis procera against alloxan-induced diabetes in rats. Journal of Ethnopharmacology2005; 102:470-473. http://dx.doi.org /10.1016/j.jep.2005.06.026 PMid:16054794
20. Rajesh R, Raghavendra CD, Gowda A, Nataraju BL, Dhananjaya K, KemparajuK, Vishwanath BS.Procoagulant activity of Calotropis gigantea latex associated with fibrin(ogen)olytic activity. Toxicon2005;46(1):84-92.http://dx.doi.org/10.1016/j.toxicon.20 05.03.012 PMid:15922393

21. David M, BharathKR, Bhavani M. Experimental investigation for pest resistant properties of Calotropis gigantea. International Journal of Pharmaceutical Applications2012; 3(3):380-386.

22. Chandrasekaran M, Venkatesalu V. Antibacterial and antifungal activity of Syzygium jambolanumseeds. J Ethnopharmacol., 2004; 91:105-108. http://dx.doi.org/10.1016/j.jep.2003.12.012 PMid:15036477

23. Bashir U, Tahira JJ. Evaluation of Eucalyptus camaldulensis against Fusarium solani. Int. J. Agric. Biol.,2012; 14:675-677.

24. Kirtikar KR,Basu BD. Indian Medicinal Plants: Plates. Vol. III, 2nd edn. Dehradun (India):Bishen Singh Mahendra Pal Singh Publishers and Distributors; 1999.p.191-92, 420-22, 993-94, 2045-47.

25. Abu-Taleb AM,Deeb KE, Al-Otibi FO.Bioactivity of some plant extracts against Drechslerabiseptata and Fusarium solani.Journal of Food2011; 9:769-774

26. Jeyaseelan EC, Vinuja T, Pathmanathan K, JeyadevanJP. Control of plant pathogenic fungi using organic solvent extracts of leaf, flower and fruit of LawsoniainermisL. International Journal of Pharmaceutical \& Biological Archives 2012; 3(4):783-788.

27. Brown HL, Bruce A. Assessment of the biocontrol potential of a Trichoderma virideisolate part I: Establishment of field and fungal cellar trials. International Biodeterioration and Biodegradation1999; 44:219223. http://dx.doi.org/10.1016/S0964-8305(99)00082-7

28. Brown HL, Bruce A, Staines HJ. Assessment of the biocontrol potential of a Trichoderma virideisolate part II: protection against soft rot and basidiomycete decay. International Biodeteriorationand Biodegradation 1999;44:225-231. http://dx.doi.org/10.1016/S0964-8305(99)00083-9

29. http://agritech.tnau.ac.in/itk/IndigenousTechKnowledge Oper.html (Retrieved on 27th May 2013)

Cite this article as:

Mandepudi David, RavuruBharath Kumar, Mandepudi Bhavani. Experimental studies on active metabolites of Calotropis gigantea for evaluation of possible antifungal properties. Int. Res. J. Pharm. 2013; $4(5): 250-254$ 